\title{
The Enhancement of Cultural Literacy of Young People: Engagement of Heritage Sites
}

\author{
Anita Stasulane \\ Daugavpils University/ Institute of Humanities and Social Sciences
}

\begin{abstract}
Based on the mapping undertaken in the EU Horizon 2020 Programme research project "Cultural Heritage and Identities of Europe's Future" (CHIEF, Agreement No. 770464), the National History Museum of Latvia in Riga and the Mark Rothko Art Centre in Daugavpils were selected to compare how the cultural heritage is represented and offered to young people in the mainstream heritage site and in the alternative heritage site. The proposed presentation will outline the results of fieldwork carried out from (February 1 - March 30, 2019) in the selected heritage sites. The data obtained from the semi-structured in-depth expert interviews made it possible to discuss: (1) the implementation of the cultural heritage policy in heritage sites; (2) understanding of the concepts "culture", "national cultural heritage", "regional cultural heritage", "European cultural heritage"; (3) the contribution of cultural heritage sites to the enhancement of young people's cultural literacy. The selection of the heritage sites provided by the strategy of the CHIEF project, i.e. to focus on the mainstream and alternative heritage sites simultaneously for the purpose of exploring the offer for young people's cultural education, has proved its worth since the comparison shows the common and different aspects, advantages and problems/drawbacks in the operation of both institutions.
\end{abstract}

Keywords: alternative heritage site, cultural education, cultural heritage policy, mainstream heritage site, national cultural heritage 